Evaluation of the applicability of investment appraisal techniques for assessing the business value of IS services

Koen Milis, Monique Snoeck and Raf Haesen

DEPARTMENT OF DECISION SCIENCES AND INFORMATION MANAGEMENT (KBI) 


\title{
Evaluation of the applicability of investment appraisal techniques for assessing the business value of IS services
}

\author{
Koen Milis ${ }^{1,2}$, Monique Snoeck ${ }^{3}$, Raf Haesen ${ }^{3}$ \\ ${ }^{1}$ Information Management, HUBrussel Stormstraat 2, 1000 Brussel, Belgium \\ koen.milis@hubrussel.be \\ ${ }_{2}^{2}$ Departement Informatiekunde, Universiteit van Tilburg, Warandelaan 2, P.O. Box 90153, 5000 LE Tilburg, \\ Netherlands \\ ${ }^{3}$ KULeuven, Faculteit Economie en Bedrijfswetenschappen, Kwantitatieve Beleidsmethoden en Beleidsinformatica, \\ Naamsestraat 69, Belgium \\ \{monique.snoeck, raf.haesen\}@econ.kuleuven.be
}

\begin{abstract}
There is a consensus among academics and practitioners that ICT investments should be carefully justified, measured and controlled. This is not different for the development of a service architecture or the development of particular services as such. In practice, the traditional capital investment appraisal techniques (CIAT's) such as payback period or net present value are by far the most used techniques for assessing the feasibility of ICT investments. Nevertheless, serious doubts about the fitness of these techniques in a service based value net environment arise. Value nets have special characteristics such as high flexibility and agility, re-use of services,... that makes the use of these techniques very difficult and the reliability of the outcome most uncertain. Efforts are made to find more appropriate techniques. In the past, CIAT's have been adjusted so that these techniques become more reliable in an ICT environment and new justification methods and techniques have been developed. However neither these adjusted techniques nor the new techniques are frequently used. This might be explained by the fact that the outcome of these techniques is difficult to interpret and to use and the fact that some significant problems (like the estimation of hidden costs) remain unsolved. Moreover, most of the new techniques are still in the conceptual phase. In this paper we evaluate these adjusted and new techniques in the light of service oriented architectures. We will argue that non of the techniques offers a good solution for assessing the business value of IS services
\end{abstract}

Despite the existence of a wealth of literature, the IS community appears to be no nearer to a solution to many problems associated with ICT appraisal. This is potentially problematic when dealing with investments in emerging technology such as IS services or service architectures. Since all techniques presented in the article have their drawbacks, it is safe to say that reliance on a sole technique may lead to sub-optimalisation or even failure. Therefore it makes sense to use a mixture of techniques, eliminating or diminishing the weaknesses of each of the techniques used. We strongly recommend a multi-layer evaluation process, or an evaluation process derived from the balanced scorecard, for the appraisal of investments in services or service architectures. 
Glossary

$\mathrm{PP}=$ Payback period

ROI $=$ Return on investment

IRR = Internal rate of return

$\mathrm{NPV}=$ Net present value

CIAT $=$ Capital investment-appraisal techniques 


\section{Introduction}

The business environment is undergoing a dramatic change. Companies are under increasing pressure to respond quickly to changing market conditions. The demand for innovation, flexibility, and shorter time to market for new products has led to rethinking industry structures. New ways of intertwining IT and business structures are sought to maximize business flexibility. Concepts such as componentization and service orientation are developed to construct new business models were the business function (service) is separated from its fulfilment (implementation), allowing an enterprise to deconstruct, analyze, and then reconstruct distinct business functions into value nets [1].

The process of deconstruction/reconstruction is realized through business components, which firms link efficiently and seamlessly with best-of-breed components provided by external partners to support their business processes [2,3]. This enables companies to swiftly adapt their processes to changing market conditions and to adapt their contemporary business model. The utilization of IT to create and support business components is referred to as IS services.

The use of a service architecture leads to new roles in the business and ICT landscape. In essence, services differentiate from other types of IT by the emergence of service intermediates. Hence, three large groups of stakeholders can be defined in a services environment. There are the service providers: they develop the services and publish the interfaces of their services to the service intermediates. The service intermediates (brokers) are the go-betweens that help the requestor to find the appropriate service. Service requestors are organisations in need of a service: they can send a request to the intermediates when looking for services. Once the service and its provider are identified, the service requestor binds to the corresponding service provider to consume its service. Each group has its own perspective on services, with their own goals and advantages.

In today's increasingly competitive business climate, there is a growing requirement for stronger cost control and a demand for higher returns while minimizing risks of investments. Recognition of the potential impact of IS services and service architectures on the strategic power of companies makes the evaluation, justification and control of such investments a critically important issue.

However, the record on measuring and controlling ICT investments has not been impressive. While financial economics is well-established and applied in many areas, there is not much data published on quantitative financial analyses for major IT-investments [4]. Most companies are still characterised by an ad hoc, unstructured, and unpredictable investment processes (phase 1 of the GAO developed maturity model) [5, 6]. Only a fraction of the organizations rely on rigorous methods to calculate the benefits of investment in IT $[4,7,8]$. The reasons for these failures can be complex: technical, human resource, environmental, organizational and management issues interrelate where explanations are sought. Major barriers, identified by a range of studies, occur in how the ICT investment is evaluated and controlled $[4,7,10,11,12]$.

Though, at this point in time, as IS services are a relatively new phenomenon, little work has been performed on the feasibility and the calculation of business value of IS service projects. Yet, as the technology and architectures go beyond the conceptual and experimental phase, the feasibility of services will become an increasingly important issue. Yet, the essence of services itself (the 
ability to adapt seamlessly to change, high levels of flexibility, agility and reuse) make it even more difficult to apply capital investment appraisal techniques (CAIT's).

This paper studies the part of the evaluation and justification process that senior managers consider being the most important: the feasibility evaluation [13]. More specifically, ex ante evaluation techniques used to justify ICT investments are discussed. They will be examined in view of their potential use to evaluate IS service investments. For each technique, strengths and weakness, downsides and potential difficulties are examined. The applicability of these techniques in an ICT environment in general and a services environment particularly are discussed.

\section{Traditional Evaluation Methods}

\subsection{Introduction}

Research strongly indicates that the feasibility study of capital investments in today's companies and organizations is mainly based on financial cost-benefit analysis, conducted using traditional capital investment-appraisal techniques (CIAT) [13, 14, 15]. Most commonly used for ICT appraisals are payback period (PP) and Accounting Rate of Return/Return On Investment (ARR/ROI). Techniques as Internal Rate of Return (IRR) and Net Present Value (NPV) -which are perceived as being more difficult- are used to a lesser extent $[15,16]$.

Moreover, when figures on the use of CIAT's from the 1990's are compared with more recent data, it becomes obvious that there is hardly any improvement in the use of CIAT's for the appraisal of IT projects. Yet, CIO's claim that the pressure to calculate the return of IT investments is increasing $[17,4]$.

Table A: Percentage of organisations using CIAT techniques to justify capital investments

\begin{tabular}{|c|c|c|c|c|}
\hline \multicolumn{5}{|c|}{ Use of capital investment appraisal techniques } \\
\hline \multirow[b]{2}{*}{ technique } & \multicolumn{2}{|c|}{ ICT investments 1990’s } & \multicolumn{2}{|l|}{ ICT investments 2000’s } \\
\hline & $\begin{array}{l}\text { Bacon } 1990, \quad \text { UK, } \\
\text { USA, Australia, } \\
\text { New Zealand }(\%)\end{array}$ & $\begin{array}{l}\text { Ballantine/Stray } \\
\text { 1998, UK }(\%)\end{array}$ & $\begin{array}{l}\text { Richardson, CSI } \\
\text { survey } 2004\end{array}$ & $\begin{array}{l}\text { Richardson, CSI } \\
\text { survey } 2004\end{array}$ \\
\hline $\mathrm{PP}$ & 61 & 60 & & \\
\hline ROI & 18 & 43 & 55 & 39 \\
\hline IRR & 54 & 28 & 28 & 17 \\
\hline NPV & 49 & 27 & 25 & 21 \\
\hline
\end{tabular}

Source: Adapted from Ballantine \& Stray, 1998 [15] and Bacon, 1994 [18]., Richardson, 2004 \& 2008 [19, 20]

\subsection{Comparing traditional CIAT's in an IS services context}

The Payback Period technique (PP) is defined as the time period needed to compensate for the initial investment expenditure using the money flow that is produced by the investment. The payback period should be considered as the least suitable CIAT for the appraisal of IT projects. Due to the fact that projects are judged on the period needed to compensate the initial investment, projects with fast payback are favoured. As a result, companies using the PP technique will tend to accept too many short-lived projects and reject too many long-lived ones [21]. In a services context this means the selection of services that deliver quick results are 
favoured. The gains generated by reuse are ignored if they are realized after the initial investment is compensated. As such, one of the fundamentals of service architecture -the reuse of servicesis not fully accounted for. Furthermore, the inability to incorporate risk into the appraisal and the ignorance of the time value of money make this technique inapt for the evaluation of IT projects. PP may be an adequate rule of thumb, but, considering the shortcomings, major investment decisions should not be based solely on the results of PP calculations.

Accounting Rate of Return (ARR)/Return On Investment (ROI) are defined as the ratio between the annual gains (measured resp. by the annual income after tax or by the cash flow) and the amount of money investment. ARR/ROI is more adequate than PP because the total lifecycle of the investment is taken into account. This technique is considered useful by IBM researchers in a services environment [3]. Nevertheless, as with PP, the time value of money is not taken into consideration. Risk can be entered into the appraisal to a certain extent by adjusting the hurdle by which the IS services are judged, but this is not useful when dealing with mutually exclusive projects (selecting between similar services offered by two different developers for example).

The Internal Rate of Return (IRR) corresponds to the rate for which the present value of the investment's money in-flows are equal to the present value of the money out-flows. Unlike the previously mentioned techniques, Internal Rate of Return (IRR) takes the time value of money into consideration by introducing a discount factor. This is a major improvement and makes this technique more useful. Still, there are some disadvantages:

- The result of IRR is a percentage. This makes it difficult to compare services that differ substantially in size and outcome. Services can vary substantially in terms of granularity and functions offered.

- If the IRR differs substantially from the cost of capital, it will become difficult to compare investments in IS services with a different time pattern.

- When this technique is used as a selection tool for mutual exclusive services, risks are not accounted for. It lacks the possibility of entering risk-levels into the selection. This is a major disadvantage, especially when used in a services architecture where levels of future use are often highly uncertain [based on 16, 21, 22].

The Net Present Value (NPV) technique calculates the present value of the investment's money flows, using a discount rate [16]. In opposite to IRR, different rates can be used to reflect the risk-levels of mutual exclusive investments. The NPV technique is considered as being theoretically superior to the IRR technique [21].

Table B: overview traditional CIAT-techniques

\begin{tabular}{|l|l|l|l|l|}
\hline & PP & ROI & IRR & NPV \\
\hline Does it consider the entire lifetime of the investment? & no & yes & yes & yes \\
\hline Does it consider the time value of money? & no & no & yes & yes \\
\hline Can risk-levels be entered into the feasibility evaluation? & no & yes & yes & yes \\
\hline Can risk-levels be entered in the selection of mutual exclusive projects? & no & no & no & yes \\
\hline
\end{tabular}




\subsection{Reasons for using CIAT techniques to evaluate IS service projects}

There is an extensive accounting and finance literature that argues that CIAT's are appropriate techniques for the appraisal of all types of investments [15]. The arguments used stem from the fundamental assumption that an organizations' primary objective is that of maximizing profit and shareholders wealth. In order to achieve these objectives a common method of appraisal is needed which can be applied equally to the whole spectrum of investment decisions [23]. This has led to an emphasis on financial appraisal techniques that are consistent with these objectives. A second argument is that, in contrast with non-traditional appraisal techniques (see infra), CIATs are well known and well understood. Business schools train their students extensively on how to use them. They are based on generally accepted principles $[15,24]$. The fact that the responsibility for all investments, including investments in ICT, has remained firmly with the finance director $[7,25]$ might explain the success of these traditional, well-understood financial techniques.

\subsection{Reasons for not using CIAT techniques to evaluate IS investments}

\subsubsection{Conceptual arguments}

\section{Parties involved}

When a company invests in the development of services, there are a number of stakeholders involved. In literature, a large number of potential roles are described, though there is no consensus on terminology: Registrar, Broker, Reseller, Biller, Authenticator, Service Aggregator, Host, Requestor, Locator, Provider [2, 26, 27]

In essence, services differentiate from other types of IT by the emergence of service intermediates and the fact that the software used to deliver the service remains the property of the service provider, rather than being acquired by the user of the service. Hence, three large groups of stakeholders can be defined: the service provider, service intermediates (though this role is not always present) and service requestors (see supra).

The service provider investment is related to the development or acquisition of a services and providing the run-time infrastructure for offering the service to service requesters. Gains are generated by the use of services by requestors. Hence, the focus of the service provider is in essence long term. The service provider will consider the gains generated during the entire lifespan of a service, including gains obtained via use of the service and reuse of the service as part of other services. Service providers have a natural tendency to strive for generic services offering ample possibilities of reuse. The service requestor wants a service that meets his specific needs in the best possible way. His investment effort is the search for services that suite his particular situation and service architecture. Hence, service requestors have a tendency to select specific solutions. Whether or not a service is reusable is not their concern. Finally, service intermediates are focusing predominately on short-term criteria. They are aimed at matching the needs of the requestor with the services offered by the provider at a particular moment in time. They are indifferent to genericity and re-use of services. They do not care whether the needs of the requestor are fulfilled using new or re-used services. The intrinsic qualities of the service are not their prime concern. Getting a match is what they aim for.

The decision to invest in IS service development is made by the service provider, who wants to optimize his financial return. Consequently, if the appraisal of an IS service development investment is solely based on CIAT's, generic services with substantial reuse possibilities will be favoured. This can be potentially harmful. The gains generated by an IS service often depend on 
the willingness and eagerness of the requestor to use these services. When the requestors are reluctant because the match between their need and the generic solution offered is not sufficiently high, the benefits are likely to diminish. On the other hand, when the requestor uses CIAT's to assess the purchase of a service, he will focus entirely on his own costs and benefits.

Yet, the evolution towards value nets implies an evolution towards a business model where entities in the network function -at least partly- as partners. Basing investment decisions solely on a CIAT technique that favours one party but does not take into account (some of) the needs of the other stakeholders is potentially harmful.

This leads to the conclusion that focusing solely on traditional financial based CIAT's, and thus on gains, can lead to a sub-optimal choice. It neglects the criteria of the other parties involved and thus fails to incorporate factors that are of crucial importance for the acceptance and the willingness of the other parties to cooperate. Therefore, focusing too much on the financial gains can diminish the benefits of a service.

\section{Conservatism}

Traditional CIATs are conservative in nature. Low risk projects are bolstered. Investments tend to be penalized if the pay-offs are likely to be long-term $[12,16,18,28]$. Hence, projects dealing with the introduction of new technology or architectures are too swiftly put aside as the gains of the acquired knowledge may only be realized far ahead in the future.

In short, one can state that the combination of high risk and long-term pay-offs can tilt decisionmaking towards the expedience of unreasonable short-term solutions. Innovation is discouraged. Overreliance on traditional CIAT can lead to an excessively conservative IT-portfolio and an associated loss of competitiveness $[12,13]$.

This applies to its full extend to IS service investments as well. Moreover, one could argue that conservatism is particularly counterproductive when dealing with emerging technology and business concepts such as services.

\subsubsection{Functional arguments}

\section{Measuring benefits}

The benefits that result from the implementation of an ICT project can be split up in three categories. The tangible benefits address the part of the investment that management can easily identify and attach a quantifiable value to. The intangible benefits are benefits that are known to the management, but which are difficult to measure or quantify. The third category of benefits are "hidden" from the decision maker. These are benefits which management either overlooks or chooses to ignore or, for one reason or another, fall beyond the boundaries established by existing investment approaches [29, 30].

Compared with other investment projects such as the construction of a bridge, the ratio of tangible to intangible and hidden benefits tends to be much smaller for ICT projects. This can be explained by the fact that ICT investments are often supportive in nature. Consequently, the chain of causation from system functionality to the factor that is of value to the company may be complex and uncertain [30, 31, 32]. In this context, Hinton \& Kaye [14] speak of iceberg investments, aiming at the fact that a large proportion of the benefits are "hidden". This is not different for IS services, since they are designed to support a business process. Moreover, a service is often just a small element in a larger set of services. It can only create value in combination with other services. The added value of certain business processes is often difficult 
to measure. Allocating the added value to the individual services that supported the process is even a bigger challenge. Furthermore, attempts to quantify benefits in financial terms involve making assumptions and medium- to long-term forecasts in an environment that is very volatile. Changes in the business and economic environment impact the business models of organisations and consequently the business processes used, making accurate estimates over possible re-use notoriously difficult. The very nature of service architectures is such that they are designed to deal with change.

Most managers are aware of the important role these intangible or hidden benefits play in the justification process of ICT investments. Willcocks \& Lester [10] found that intangible benefits of IT systems were widely perceived by senior managers as being as important as harder financial benefits. In his survey, Kirkpatrick [17] found that only 30\% of the CIO's are confident that monetary/business value metrics fully capture the value of major IT projects, indicating the fact that they expect substantial intangible or hidden benefits.

\section{Measuring costs}

Although costs are more easily measured than benefits, part of the costs of an ICT investment are also intangible or hidden [24, 28]. Up to $65 \%$ of ICT managers suggest that they were probably failing to identify full cost through the formal evaluation process $[28,33]$.

A traditional example in this context is the cost that arises from a temporary descend of efficacy due to the switch from one business process to another. These costs are seldom fully accounted for. Similar to the allocation of benefits is the allocation of some of the cost to individual IS services extremely difficult.

\section{Discount rate}

Following traditional CIAT methodology, risks should be reflected in a higher discount rate [24, 35]. There are several risks in connection with IS services.

- assessment risk: the failure to build in adequate risk assessment of different options at the prioritization and feasibility stage of service development projects constitutes a risk in itself.

- technical risk: the service and the envisioned capability are not feasible with the current technology.

- project risk: the capability that a firm seeks to develop is too large or too complex, or overwhelms the staff's technical skills. The implementation may be less than smooth. Additional implementation time can add very large cost burdens. The lack of a contingency plan (for example the replacement of personnel) might cause high additional costs.

- functional risk: the firm may get the system design or implementation right - that is, according to specification - but still fail to realize the anticipated benefits. The system analysis may have failed to assess the needs of the requestors accurately or the target moved in an unexpected way $[24,28,32,34]$.

However, traditional capital asset pricing models that underlie CIAT approaches fail to provide ways to compose discount rates properly when dealing with ICT investments and IS services [35]. Hence, there are no generally accepted methods or techniques to quantify the risks and to incorporate them in the discount rate. Ballantine \& Stray [15] for example, found that only $7 \%$ of the organizations adjust the discount rate in function of the potential risks of an ICT project. But 
even when managers intend to adjust the discount rate, the discussion about the risk levels is emotional and not based on numbers [12]. Nevertheless, the choice of an appropriate discount rate should be a concern for managers dealing with investment evaluation. Not adjusting the discount rate in function of potential risks could lead to a portfolio that bolsters high-risk projects, over-adjusting could lead to a portfolio of services that is too conservative [24].

\subsection{Traditional feasibility evaluation: conclusions}

Evaluation and justification of services is a serious challenge. Although accounting and finance literature state that CIAT are the appropriate techniques to evaluate all capital investments, there are simply too many conceptual and functional uncertainties to use these techniques in an efficient way for the feasibility evaluation of Information System services.

\section{Adjusted Traditional Evaluation Methods}

\subsection{Introduction}

There is a large consensus in ICT literature that traditional CIATs are not appropriate to evaluate ICT investments. Consequently, efforts have been made to present alternatives. These attempts can be categorized in two major groups.

A first group of techniques are based on the traditional CIATs. Adjustments are imposed in order to meet the most important criticisms. The choice to adjust the traditional CIATs has a double goal. On the one hand, the authors want to develop techniques that are better suited for the feasibility evaluation of ICT-investments. On the other hand, choosing traditional CIATs means choosing for a solid and well-understood foundation. The canvas stays similar with the canvas of the traditional CIATs, so that a comparison with other capital investments remains possible. A second group of attempts are characterized by a complete break with the traditional CIATs. The evaluation and justification of ICT-investments is looked at from a completely different and new perspective.

In the next sections an overview is presented of the most important adjusted \& new techniques. Special attention is given to their applicability for the appraisal of IS services or service architectures.

\subsection{Adjusted cost / benefits estimates}

Estimating costs and benefits is a major problem when using the traditional CIATs (see supra). Several authors propose techniques to incorporate adjusted estimation into the CIATs.

Willcocks [28] for example, suggests that managers should enter alternative estimates of intangible benefits (e.g. minimum and maximum values) into the NPV model to explore the project's sensitivity to the delivery of these intangibles. The range or sensitivity delivers additional information that can be used by the management to make investment decisions $[11,12,28]$. This technique can be used for the appraisal of IS services as well. For example: estimates can be made of the minimum and maximum gains derived from the re-use of services, resulting in a minimum and maximum return. 
Another approach is the use of expected values in the NPV technique. Expected values are obtained by multiplying the probability of the realization of an expected benefit by its estimated value. Often, when this approach is mentioned in the literature, references are made to option and future value calculating theories [11,35]. As with options and futures, one is dealing with uncertain gains that are the direct consequences of an investment. This technique is particularly suitable when considering services with high levels of expected re-use. In that case, the expected return of the re-use is calculated and multiplied by the chance of realisation.

\subsection{Discount rate sensitivity}

As stated previously, the choice of an appropriate discount rate is notoriously difficult. The discount rate should not only reflect the cost of capital, inflation and taxes, but should reflect risk as well. Managers should be aware of the impact of an over- or under assessment of the discount rate. A sensitivity analysis can help gain insight in the possible effects of an ill-chosen discount rate. A display of ranges in risks will enhance the credibility of the proposed investment [12].

\subsection{Adjusted interpretation process}

Earl [11] and Whiting et al [31] suggest a different and more pragmatic approach. They do not try to alter the traditional techniques as such, rather, they suggest a different way to apply and interpret these CIATs. A three-step approach is suggested:

- Calculate the NPV for cash flows of the tangible benefits and the costs.

- If this NPV is positive, accept the project.

- If it is negative, calculate the values required from the intangible benefits to make it zero and then assess the probability of achieving these values.

Implicitly, this approach is based on the assumption that costs are easier to assess than benefits. It is assumed that the amount of hidden or intangible costs is negligible or at least far exceeded by the intangible benefits.

\subsection{Adjusted traditional CIAT: discussion}

The fundamental criticisms on the traditional CIATs are not solved entirely. It remains difficult to assess costs and benefits and to incorporate risk, and this is even more difficult in the context of IS services. New parameters (e.g. probability figures/functions, risk adjustment quotient) need to be generated to use these techniques. The estimation of these parameters is a somewhat subjective matter [31] and can therefore be manipulated.

Another problem with the adjusted techniques is the interpretation by the management. The interpretation is not as straightforward as with not-adjusted NPV, especially when the outcome of the adjusted technique is a range of possible values. Companies tend to choose for the payback period and ROI because these techniques are perceived as being "more easy" than IRR and NPV. Consequently, it is very doubtful that techniques with adjusted cost/benefit estimates or risk sensitivity will become popular.

Nevertheless, the adjustments proposed can lead to a more accurate and more profound decision platform for management. 
The last approach, the adjusted interpretation process, is an approach that has grown out of practical experience. A weak point in this technique is the assumption that the intangible costs are negligible. On the other hand, this technique is easy to use and comprehensive for managers. This technique can easily be used within a multi-layer evaluation process (see infra) $[11,31,36]$.

\section{New Evaluation Techniques}

\subsection{Introduction}

Many scientists and practitioners remain sceptical on the (adjusted) traditional CIAT's. They have started to develop new techniques. These techniques are characterized by a complete break with the traditional finance based techniques. New angles are being searched for. As with most things under development, the field of ICT investment appraisal is still fuzzy and shows signs of immaturity. A wide variety of different approaches arise [31]. In most cases, these techniques are still in a conceptual phase. The number of implementations is limited, if any. None of these nontraditional techniques have been generally accepted for traditional software development [24], let alone for service oriented development.

In this section an overview of the non-traditional feasibility evaluation techniques is presented and their use in a service environment is discussed. This overview is by no means complete. The aim is to present a general view of the different directions in which the search for evaluation techniques evolves.

\subsection{Strategic fit}

The strategic fit approach, originally proposed by Porter [37] explicitly addresses the strategic dimensions of the competitive advantage perspective on management [38]. ICT investments should be evaluated primarily in function of their contribution to a firm's competitive advantage. Interviews performed by Coleman and Jamieson [32] revealed that besides the (adjusted) traditional evaluation techniques, only strategic fit was mentioned by a high proportion of the respondents as a technique used in evaluating ICT projects.

Transposing this approach to a services environment, the appraisal of an investment in a new IS service is based primarily on the expected contribution of this service to the business process it supports. In its purest form, the strategic fit approach does not give explicit attention to financial analysis [38]. As such, this approach provides guidelines to select between services of a different kind, but it is not helpful when a company needs to choose between two mutually exclusive services, both serving the same purpose.

\subsection{Information economics}

M. Parker and R. Benson devised the information economics framework. They first published on the subject in $1987[39,40]$.

Information economics (IE), in essence, uses a process of assigning point-rating scores to assess the investment benefits and strategic relevance of ICT technologies. IE prescribes a procedure, to be executed in a certain sequence $[12,40]$ : 
- form a committee of evaluators

- obtain consensus on intangibles

- quantify the importance of benefits and risks on a relative scale

- estimate the probabilities on a scale of zero to five

- multiply each estimate by the weight and probabilities

- sum the numbers. Select the best alternative as one that has the largest sum.

The problem with this approach is that it relies entirely on consensus of subjective opinions. The technique lacks independent authentication [12]. Average consensus ratings, as the IE practice dictates, blur or eliminate the possibility of accountability. Verifiable inputs do not enter into these deliberations in any formal way, except when a participant argues to give a favoured option a greater scoring weight. It is impossible to link the synthesized rating to business plans or to cash flow projections [12]. Following this methodology, the task of the CIO is limited to convincing the finance committee of the merits of the relative weights in the tables.

This approach is perfectly applicable in a services environment. A list of wanted tangible and intangibles benefits and risks can be constructed and every service can be scored on each item of the list. This way, a ranking of services to be developed is created. Though, the fundamental criticism on this approach remains: the selection is made based upon opinions and is thus subjective in nature.

\subsection{The options model}

Option models are not only used to adjust traditional CIATs (see supra), but some new evaluation methods are based on option models as well. A growing volume of research has been performed into IT investments and real options theory [41, 42, 43].

The origin of this type of feasibility evaluation methods is in the valuation of complex financial transactions such as stock trading, currency arbitrage and pricing of currency futures. These financial models track, store and analyze not only what happened, but what could have happened if the model had made a bet on an option. The model can then dynamically adjust its structure and coefficients to improve its chance next time the computer recommends making another bet. In this approach, ICT investments are perceived as a "bet" which might result in revenues in the future [44]. The Cox-Rubenstein equation is an example of an option model that has been used as a basis to build a new feasibility evaluation method [12, 44].

There are however doubts about the effectiveness of these methods for ICT projects:

- The quality of the outcome does not only depend on the model used, but depends on the input as well. Poor quality of data, inconsistencies and lack of rigor in dealing with non-quantifiable effects make data gathering about computer investment proposals and their results extremely difficult.

- ICT investment proposals are relatively rare events as compared to the frequency of financial transactions. Some doubt rises if option models are a good basis to start from.

- The mechanisms behind option models are difficult to understand and difficult to apply, which raises questions about their utility.

Nevertheless, applying option theory in a service environment does have an advantage over regular ICT investments: the development of a service happens far more frequent compared to the implementation of -for example- an ERP system. Though, before these techniques can be 
accepted, the proponents must first demonstrate the applicability of these techniques in managing portfolios of services. They would need to show how to gather and evaluate data that would make the planning and allocation of scarce funds a repeatable and verifiable experiment [12].

\section{Mixed Methods}

\subsection{Introduction}

Adjusted CIATs, nor any of the new techniques are generally accepted. Each technique has its own strengths and weaknesses. It is thus sensible to use a combination of different techniques and methods to rub out the weaknesses inherent to the use of a single technique. Several authors have formulated possible solutions in that direction.

\subsection{Multi-layer evaluation process}

A multi-layer evaluation process uses different evaluation techniques, which are more or less ordered in a hierarchical manner. Often, a combination of strategic fit and an (adjusted) CIAT is suggested. On the one hand, there is a widespread believe that ICT investment appraisal can only be effective if the appraisal process is embedded in higher-level business processes (strategic fit) $[31,45]$. On the other hand, CIAT are not completely abandoned since these techniques offer some unmistakable advantages [11, 45].

This usually results in a bi- or multilayer process. In a first stage, all investments that do not contribute to the strategic or business aims of the company will be rejected. In the second stage, a selection is made between the remaining investment projects, based on one or more (adjusted) CIATs.

Earl [11] and Meredith \& Hill [36], for example, suggest to split up this second stage in three substages:

1. Use the NPV technique based on the tangible costs \& benefits (quantitative approach).

2. List intangible costs and benefits (qualitative approach).

3. Make an analysis of the risks and uncertainties.

Management should then base their decision on the information presented.

As far as services are concerned, Bieberstein [3] suggest a combination of a return on investment (ROI) and the evaluation of IT efficiencies (e.g., reuse and reduced development costs). In other words, he combines a financial evaluation tool with typical technical criteria. Though, he does not elaborate on the way in which these technical criteria should be operationalized or assessed.

Clearly, the combination of different appraisal techniques and methods is also a valuable way of dealing with services. Even more so, given the fact that elements such as reuse and fast changing value nets make it notoriously difficult to make good estimates of benefits and risks. 


\subsection{Balanced score card}

Kaplan \& Norton developed a framework that helps top management to select a set of measures that provide an integrated look at a company [46]. They suggest four groups of measurable items (= four scorecards).

1. The financial scorecard contains the traditional financial performance measures. The company should set financial goals and select a limited set of financial measures.

2. The customer scorecard deals with the question "how do customers see us?" Again, goals are set and measures are selected.

3. The internal business scorecard provides goals and measures concerning the internal operations. The underlying question here is "What should we excel at?".

4. The fourth scorecard deals with the innovation and learning perspective. Can we continue to improve and create value?

To illustrate the use of the balanced scorecard, Kaplan \& Norton included an interesting example in their article [46]. An IT-company used the balanced scorecard framework to select a number of metrics and to set a number of targets for top management (figure A).

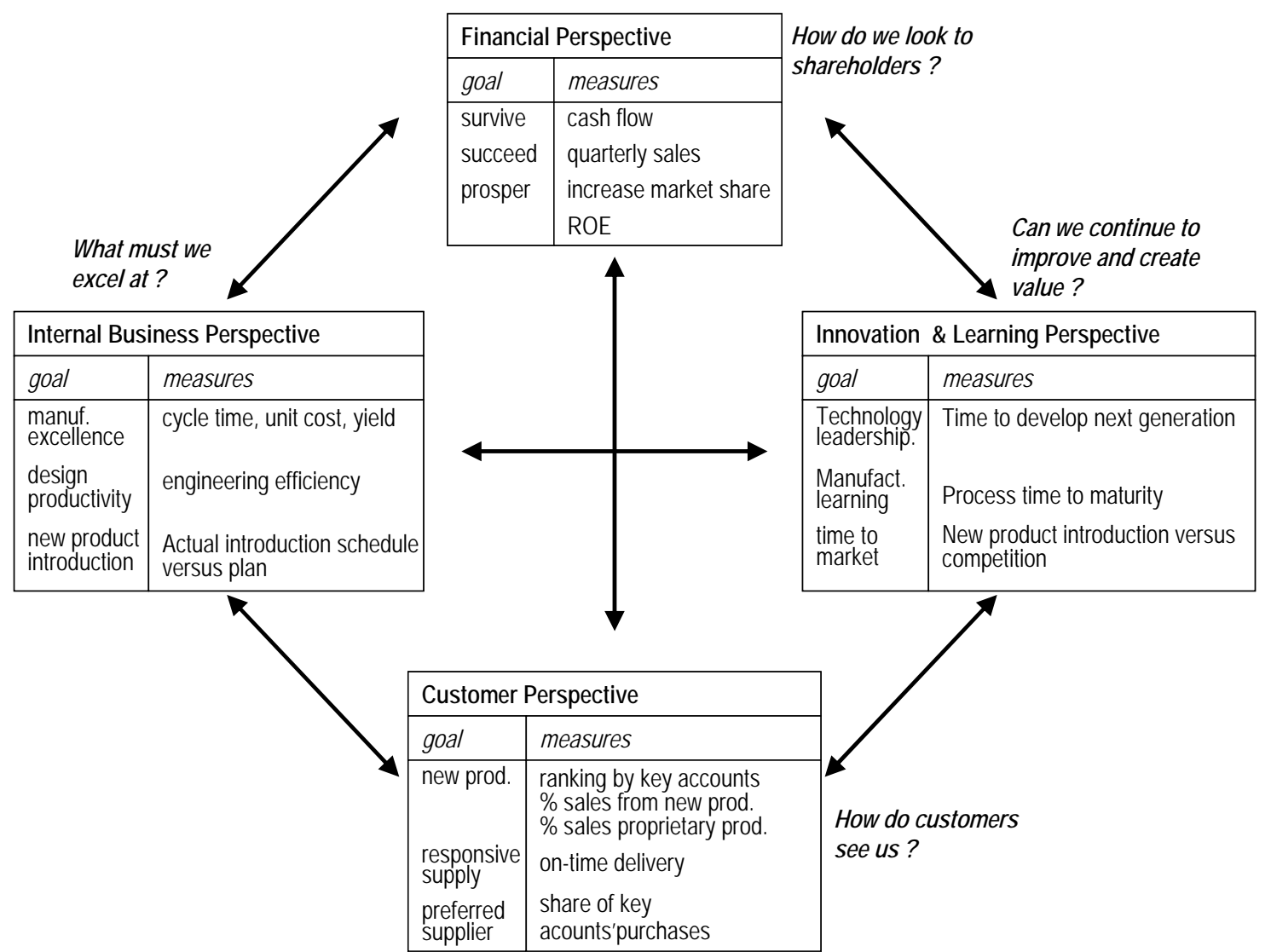

Figure A: example of the balanced scorecard framework for an IT-company

It is relatively easy to tailor the balanced scorecard framework to the specific needs of IT investment evaluation. Willcocks \& Lester [10] illustrate this with a case, based on their experience with a major European ferry company (see Figure B). When looking at this method more closely, one can conclude that this framework is a mixture of (traditional) CIATs and new evaluation methods. On the one hand, the (traditional) finance based evaluation techniques are 
not abandoned (financial perspective) [10,46]. On the other hand, the metrics used in a balanced scorecard framework are aligned to the company's strategy and business aims, which stimulate a strategic fit.

The balanced scorecard encourages a shift from financial based evaluation techniques to strategy and vision. This is as a result of the balanced scorecard needing substantially more input from the top management than does the traditional techniques. Traditional techniques in most cases are designed and overseen by financial experts [46].

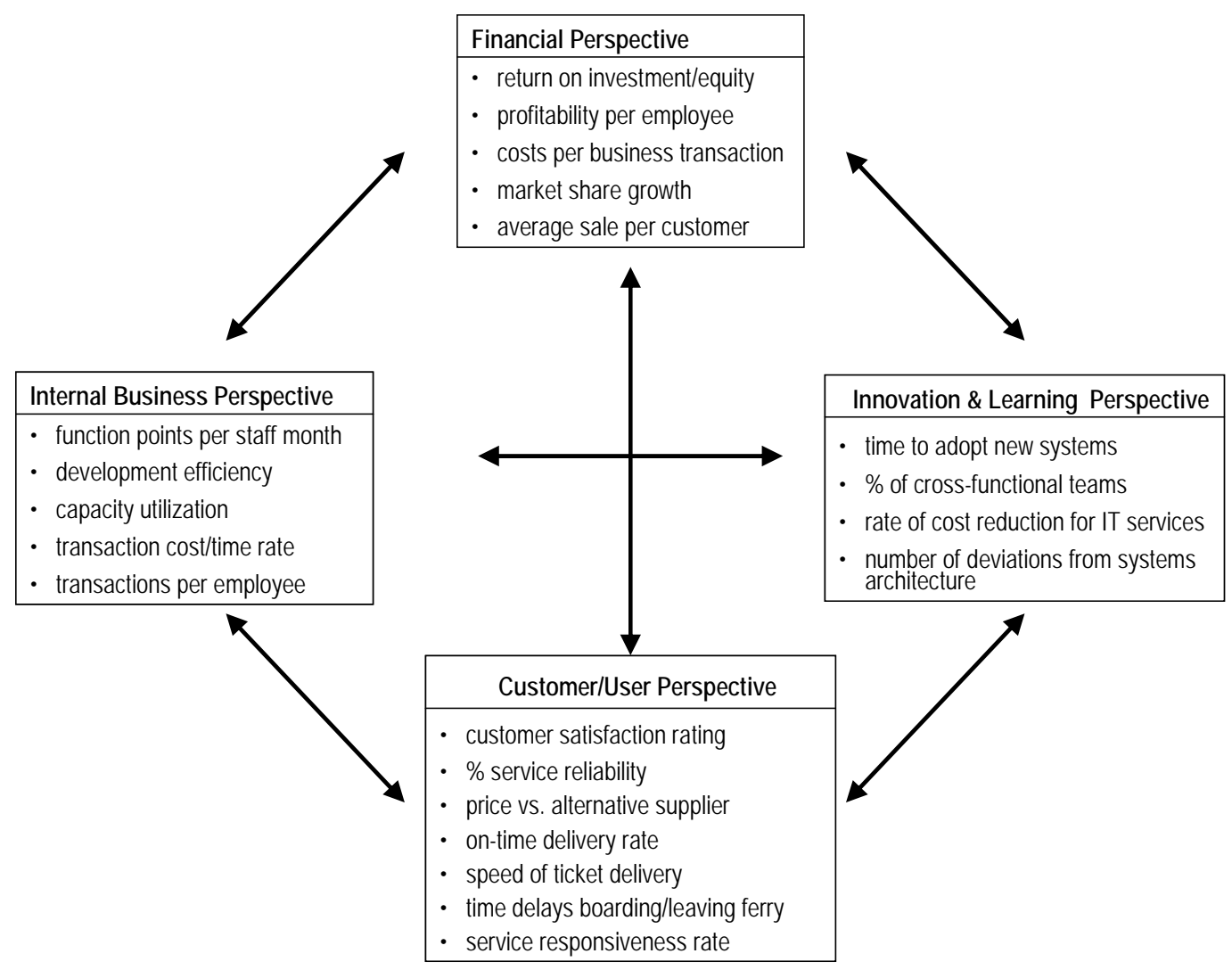

Figure B: IT-related metrics for a major European ferry company

The balanced scorecard forces management to take a broad view on ICT investments. This is one of the main advantages of this method. Another advantage is that many different evaluation techniques can be integrated into the framework. The financial scorecard can, for example, contain the ROI, NPV or any other (adjusted) CIAT. A further advantage is that the framework can be used for the feasibility evaluation and also for the follow up and ex-post evaluation.

Nevertheless, there are some disadvantages and pitfalls when using the balanced scorecard for the evaluation of ICT investments. First of all, there are probably no generic IT measures that fit all organizations. Metrics must fit a specific organization's goals, activities and customer base [10]. Secondly, when using the balanced scorecard for IT purposes, the perspective might be too narrow if the scorecard is just seen from an IT department perspective [10]. The customer perspective is reduced to the perspective of the internal users and the financial perspective might come to be interpreted as: How do we in IT appear to senior management? A view that is too narrow can jeopardize the strategic fit.

It takes little inspiration to transform the scorecard suggested by Willcocks to a scorecard that can be used for the feasibility evaluation of services. 


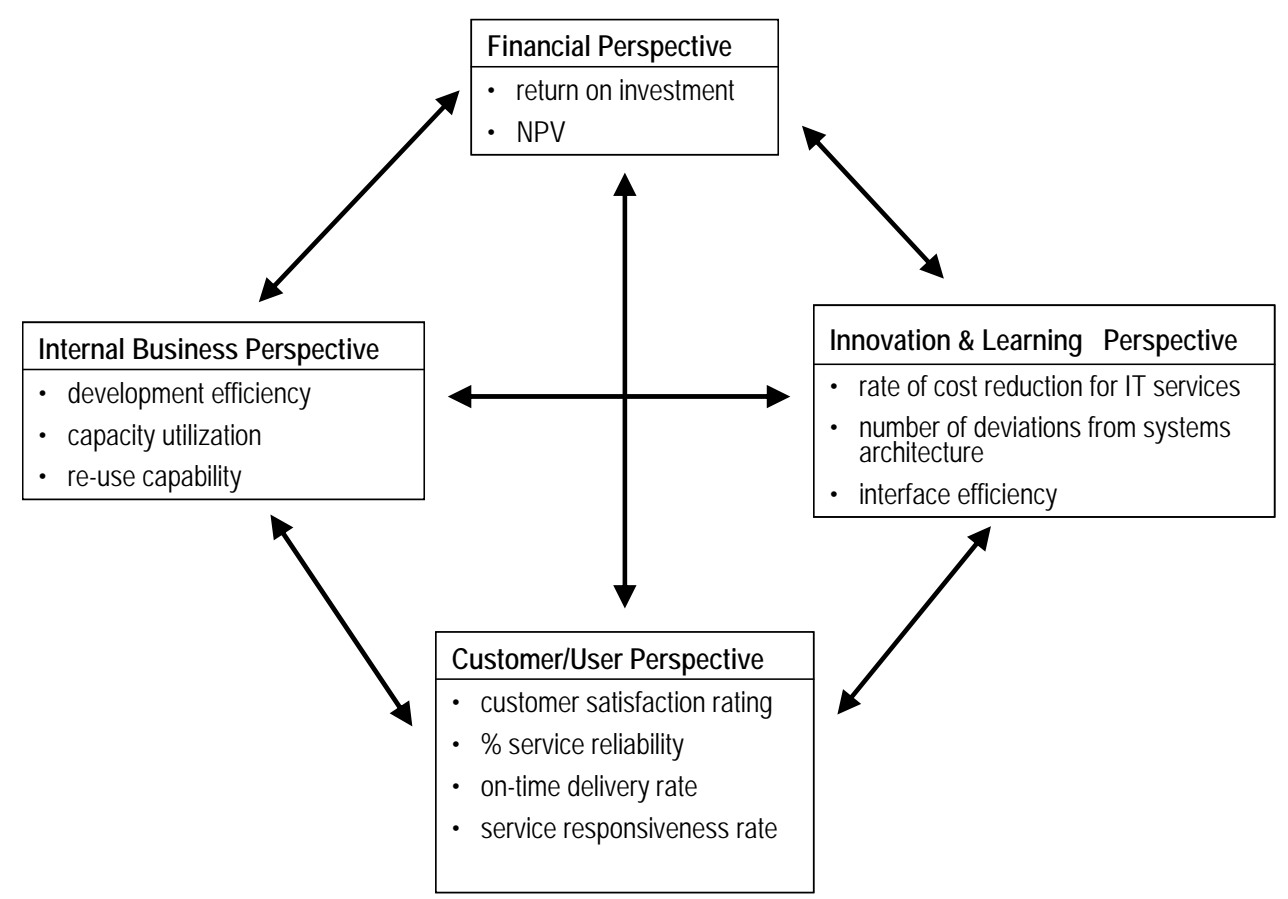

Figure C: services scorecard

If a scorecard perspective is applied for services (as suggested in figure C), the aim is no longer to ensure a good alignment between strategic goals and operations, rather, it is a way to force managers to look at services from different angles. The appraisal of services should not be based solely on financial techniques. Other elements such as potential for re-use should be taken into consideration. In particular, the internal business perspective represents is very close to the perspective of the provider, whereas the customer/user perspective defines the typical aspects relevant for a service requestor.

\section{General Conclusions}

There is a large consensus among academics and practitioners that ICT investments should be carefully justified, measured and controlled. A strong correlation exists between the control and measurement of IS and higher effectiveness with IS, however measured [38]. Investments in IS service are no exemption to this rule. There is far less consensus on the techniques that should be used to justify or evaluate services. As traditional CIATs are by far the most used techniques, one can assume that these techniques will be used when dealing with IS services as well. They are well-known, well-understood and easy to use. They are primarily focused on financial gains and are developed to maximize shareholder profits. The fact that most decisions on ICT investments are still taken by the financial department might add to the choice for these traditional techniques. Nevertheless, serious doubts about the fitness of these techniques in a services environment arise. IS service investments have special characteristics which makes the use of these techniques very difficult and the reliability of the outcome most uncertain.

The fact that most managers are aware that traditional CIATs may lead to incorrect conclusions [46] combined with the fact that traditional CIATs are by far the most used justification techniques for the feasibility evaluation of ICT projects leads us to conclude that either management tends to overestimate the efficacy of their evaluation procedures [13] or that the 
results of these procedures are simply ignored [15,46]. Consequently, attempts of using traditional CIAT's in a service environment where elements such as potential re-use and the agility and flexibility of value nets further impede the proper use of these techniques seem doomed to fail.

Efforts are made to adjust the CIATs, so that the outcome becomes more reliable. Some authors suggested ways to incorporate ICT-specific risks, others suggest new ways of calculating cost and benefits or new ways to execute and interpret the CIATs. The adjustments proposed take away part of the criticisms on the traditional CIATs, but despite the advantage over the traditional CIATs, these adjusted techniques are seldom used to evaluate ICT investments [7, 15, 31]. This might be explained by the fact that the adjusted CIATs are significantly more difficult to use and to interpret and the fact that some significant problems (like the estimation of hidden costs) remain unsolved. These criticisms apply to their full extend to the development of IS services or infrastructure as well. Moreover, it might prove even more difficult to make good estimates of the benefits, risks and costs since services only contribute to the business as part of a larger set of services.

A third group of justification methods / techniques are characterized by a complete break with the traditional finance based CIATs. New angles are sought. Most of these new techniques are still in the conceptual phase. Consequently, none of these techniques are generally accepted [24]. Though, due the property of re-use, real option theory appears to be a promising technique, though further research into the applicability of this technique in a services environment is needed.

Despite the existence of a wealth of literature, the IS community appears to be no nearer to a solution to many problems associated with ICT appraisal [15]. Since all of these techniques have their negative points, it is safe to say that reliance on a sole technique may lead to suboptimalization or even failure. Therefore a fourth group of justification methods is developed that uses a mixture of techniques, eliminating or diminishing the weaknesses of each of the techniques used (multi-layer evaluation, the balanced scorecard approach). We strongly suggest using a multi-layer evaluation process or an evaluation process derived from the balanced scorecard for the appraisal of IS services.

There are ample opportunities for further research in the area of business value, feasibility en evaluation of IS services. Not much work has been done on the subject. Though, as this paper points out: some techniques such as option theory and scorecards for IS services hold promising perspectives, but should be explored more in-depth in future research.

\section{Acknowledgement}

This research has been funded by National Bank of Belgium, project NB/08/06.

\section{References}

[1] Homann, U., Rill, M., and Wimmer, A. (2004). Flexible value structures in banking. Communications of the ACM, 47(5):34-36.

[2] Cherbakov, L., Galambos, G. M., Harishankar, R., Kalyana, S., and Rackham, G. (2005). Impact of service orientation at the business level. IBM Systems Journal, 44(4):653-668

[3] Bieberstein, N., Bose, S., Walker, L., and Lynch, A. (2005). Impact of service-oriented architecture on enterprise systems, organizational structures, and individuals. IBM Systems Journal, 44(4):691-708. 
[4] Verhoef C., Quantitative IT portfolio management, Science of Computer Programming 45 (2002) 1 96

[5] United States General Accounting Office, Information technology investment management-a framework for assessing and improving process maturity, 2004, Available via: http://www.gao.gov/new.items/d04394g.pdf

[6] Jones, C., Software Assessments, Benchmarks, and Best Practices, Information Technology Series, Addison Wesley, 2000

[7] Hochstrasser B. \& Griffiths C. Controlling IT investment: strategy and management. Kobler unit, Chapman \& Hall, 1991

[8] Love, P.E.D., Zahir Iranib and Edwards D.J., Researching the investment of information technology in construction: An examination of evaluation practices, Automation in Construction Volume 14, Issue 4, August 2005, Pages 569-582

[9] Fitzgerald G., Evaluating information systems projects: a multidimensional approach. Journal of Information Technology, 14, pp. 17-30, 1998

[10] Willcocks L. \& Lester S., Evaluating the feasibility of information systems investments: recent UK evidence and new approaches. In "Information management: the evaluation of information systems investments" (ed. L. Willcocks), Chapman \& Hall, 1994

[11] Earl J.M., Management strategies for information technology, Prentice Hall, 1989

[12] Strassmann P.A., The squandered computer: evaluating the business alignment of information technologies. The Information Economics Press, 1997

[13] Willcocks L. \& Lester S., The evaluation and management of information systems investments: from feasibility to routine operations, In "Investing in information systems: evaluation and management" (ed. L. Willcocks), Chapman \& Hall, 1996

[14] Hinton C.M. \& Kaye G.R., The hidden Investments in Information Technology: the role of organizational context and system dependency. International Journal of Information Management, Vol. 18, No. 6, pp. 413-427, 1996

[15] Ballantine J. \& Stray S., Financial appraisal and the ICT investment decision making process. Journal of Information Technology, 14, pp. 3-15, 1998

[16] Apostolopoulos T.K. \& Pramataris K.C., Information technology investment evaluation: telecommunication infrastructure. International Journal of Information Management, Vol. 19, No. 4, pp. 287-296, 1997

[17] T.A. Kirkpatrick, Research: CIOs speak on ROI, CIO Insight, 2002 1(11). Available via: www.cioinsight.com, results of questionnaire available via: common.ziffdavisinternet.com/ download/0/1396/0110 rio research.pdf

[18] Bacon J., Why companies invest in information technology. In "Information management: the evaluation of information systems investments" (ed. L. Willcocks), Chapman \& Hall, 1994

[19] Richardson R., 2004 CSI Computer Crime \& Security Survey, available via http://i.zdnet.com/blogs/, 2004

[20] Richardson R., 2008 CSI Computer Crime \& Security Survey, available via http://i.zdnet.com/blogs/csisurvey2008.pdf, 2008

[21] Brealey R.A., Stewart C.M. \& Marcus A.J., Fundamentals of corporate finance. McGraw-Hill, Inc., 1995

[22] Manigart S. \& Ooghe H., Investment selection methods. Management for engineers (Dutch language), Vol. 11, 4.3.1., pp. 1-18, 1994

[23] Lumby s., Investment appraisal and related decisions. Van Nostrand Reinhold, London, 1981

[24] Clemons E.K. \& Weber B.W., Strategic information technology investments: guidelines for decision making. Journal of Management Information Systems, Vol. 7, No. 2, (fall 1990), pp. 10-31, 1990

[25] Ballantine J.A., Galliers R.D. \& Stray S.J., Information systems/technology evaluation practices: evidence from UK organizations, Journal of Information Technology, 12, pp. 129-141, 1996 
[26] Brown, A., Johnston, S., and Kelly, K. (2002). Using service-oriented architecture and componentbased development to build web service applications. Rational Software White Paper, http://www128.ibm.com/developerworks/rational/library/510.html.

[27] Budgen, D., Brereton, P., and Turner, M. (2004). Codifying a service architectural style. In COMPSAC '04: Proceedings of the 28th Annual International Computer Software and Applications Conference (COMPSAC’ 04), pages 16-22, Washington, DC, USA. IEEE Computer Society.

[28] Willcocks L., Information management: the evaluation of information systems investments, Chapman \& Hall, 1994

[29] Murphy. K.E. and S.J. Simon.. Intangible benefits valuation in ERP projects. Information Systems Journal, 12:301-320. 2002

[30] Stefanou, C.J.. A framework for the ex-ante evaluation of ERP software. European Journal of Information Systems, 10:204-215, 2001

[31] Whiting R., Davies J. \& Knul M., Investment appraisal for IT systems , In "Investing in information systems: evaluation and management" (ed. L. Willcocks), Chapman \& Hall, 1996

[32] Coleman T. \& Jamieson M., Beyond return on investment: evaluating all the benefits of information benefits, In "Information management: the evaluation of information systems investments" (ed. L. Willcocks), Chapman \& Hall, 1994

[33] Strassmann P., The business value of computers. The Information Economics Press, New Canaan, 1990

[34] Willcocks L. \& Margetts H., Risk and information systems: developing the analysis, In "Information management: the evaluation of information systems investments" (ed. L. Willcocks), Chapman \& Hall, 1994

[35] Dos Santos B., Justifying investments in new information technologies. Journal of Management Information Systems, Vol. 7, No. 4 (spring 1991), pp. 71-90, 1991

[36] Meredith J.R. \& Hill M.M., Justifying new manufacturing systems: a managerial approach. Sloan Management review, 1987.

[37] Porter M., Technology and competitive advantage. Journal of business Strategy, winter 1985 [33]

[38] Shank J.K. \& Govindarajan., Strategic cost analysis of technological investments. Sloan Management Review, Fall 1992, 34(1), pp. 39-51, 1992

[39] Parker M.M., Trainor H.E. \& Benson R.J., Information strategy and economics: linking information systems strategy to business performance. Prentice Hall International Inc, 1989

[40] Wiseman D., Information economics: a practical approach to valuing information systems, In "Information management: the evaluation of information systems investments" (ed. L. Willcocks), Chapman \& Hall, 1994

[41] Bardhan I, Bagchi S., Sougstad R., Prioritizing a portfolio of information technology investment projects, Journal of Management Information Systems 21 (2) 2004.

[42] Singh C., Shelor R., Jiang J., Klein G., Rental software valuation in IT investment decisions, Decision Support Systems 38 (1) 2004.

[43] Hilhorst C., Ribbers P., van Heck E., Smits M., Using Dempster-Shafer theory and real options theory to assess competing strategies for implementing IT infrastructures: A case study, Decision Support Systems 46 (2008) 344-355

[44] Moad J., Time for a fresh approach to ROI. Datamation, February 15, 1995

[45] Willcocks L., Investing in information systems: evaluation and management. Chapman \& Hall, 1996

[46] Mcgolpin (1996), in Whiting et al, 1996

[46] Kaplan R.S. \& Norton D.P., The balanced scorecard: measures that drive performance. Harvard Business Review, January-February, pp. 71 - 80, 1992 